\title{
A CASE OF MYASTHENIA GRAVIS OPERATED ON FOR PTOSIS BY HESS'S METHOD
}

BY

\author{
DAVID HARDIE
}

ABERDEEN

(WITH PHOTOGRAPH AND ADDENDUM BY W. H. KIEP, BRADFORD)

MYASTHENIA gravis being a somewhat rare disease the foliowing case which occurred in my practice seems to be worth recording. The most interesting point is the satisfactory result obtained by operation for ptosis, which was the most disabling symptom.

The patient was a man, aged 38 years, a compositor by trade. There was nothing significant in his past history or in his family history, nor had he had any previous trouble with his eyes, except that he had always been short-sighted. He had never worn glasses.

His present illness began in September, 1925, when he noticed that he was not seeing so well, and that when he was reading the words tended to run together.

Early in October, 1925, he began to have some difficulty in keeping his eyes open in the afternoon, and occasionally he noticed that he was seeing double. Dr. Eurich saw him in consultation at this time and established the diagnosis of myasthenia gravis. The blood gave a negative reaction to the Wassermann test. Pluri-glandular treatment was tried, but the result was disappointing. The patient's condition grew gradually worse, until he could keep his eyes open only for a few minutes at a time, when, in spite of strong efforts to keep his eyes open, the lids would close down. After an interval of rest the eyes could be reopened, but, with repetition of the process, the period during which the eyes could be kept open grew shorter, whilst the interval of rest before they would reopen grew longer. Moreover, when the eyes were open diplopia was now always present, so that the patient was quite incapacitated from going about, or from reading, and he became very miserable and depressed.

The external muscles of the eyes and the levator palpebrae superioris on both sides seemed to be the only muscles affected. Both fundi were quite normal and vision in both eyes with $-1.50 \mathrm{D}$. sph. was normal.

It was, therefore, thought that, if a ptosis operation could be 'done, the patient's general condition would be improved, and Mr. Kiep, who saw him in April, 1926, agreed with this and suggested that Hess's operation would probably give the best result. At the same time, on account of the diplopia, he proposed 
to operate on one side only, and this was done (vide Mr. Kiep's note and photograph).

The result has fulfilled our expectations, as the patient can now open and close the (left) operated eye at will. His general condition has greatly improved, and he is much less depressed. He can now go about by himself, and can read for half to three-quarters of an

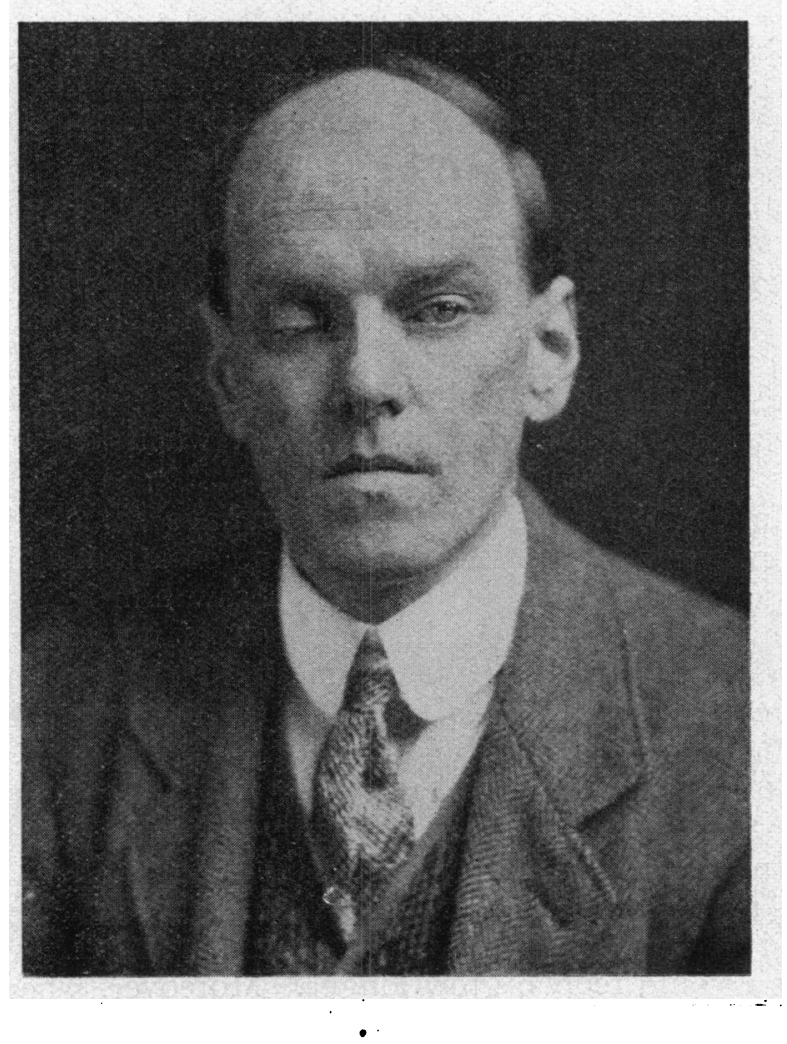

hour without discomfort. He complains of a dragging sensation in the unoperated eye when he moves the open eye in any direction, and, if he holds the right eye open, the diplopia is at once manifest. He is very well satisfied, however, with the result of the operation; and seeing that up to the present the myasthenic condition does not appear to have affected the internal muscles of the eyes, nor to have spread to the muscles of the face, trunk, or limbs, operative treatment seems to have been justified.

The photograph which was taken by Mr. Kiep in January, 1927, shows very well the ptosis of the right eyelid, and the excellent position in which the left eyelid is now maintained without effort. 
Astalos records a somewhat similar case, but, as there was no diplopia, Hess's operation was performed on both sides with a satisfactory result. ${ }^{(1)}$

Peters describes a case in which he operated by Pagenstecher's method,(2) and Braunschweig operated on the brother of Peters' case. ${ }^{(3)}$

These are the only references to operation in cases of myasthenia gravis that we have been able to find and it would be interesting to know if there are many similar cases which perhaps have not been recorded.

It appears to be recognized that cases of myasthenia gravis do occur in which the symptoms either remain confined to the eye muscles $^{(4)}$ or spread to other parts of the body only after long intervals of months or even years ${ }^{(5)}$; so that it would seem worth while in all but very acute cases to consider operative treatment where ptosis is a prominent and disabling feature.

Addendum by Mr. W. H. KiEP.

Hess's operation was performed on left upper eyelid on May 6 , 1926, the drooping of the lid being over-corrected. Patient made an uneventful recovery and when I saw him some six months later asked to have the other eye done. On account of the persistent diplopia, however, it was not considered wise to do the right side.

\title{
REFERENCES
}

1. Aszalos, E.-Klin. Monatsbl, f. Augenheilk., Bd. 73, SS. 445-447, 1924.

2 and 3.-Peters.--Ueber Myasthenia und Ptosis. Korresp. Blätt. d. Allg. Mecklenburg. Aerztvercins, Nr. 262.

4. Jaffey.-Ophthalmic Year Book, (Chicago), Vol. XXI, p. 47, 1925.

5. Taylor.-Trans. Ophthal. Soc. U.K., Vol. XXXVIII, p. 168, 1918.

\section{SERIOUS HAEMORRHAGE FROM THE CONJUNCTIVA IN AN INFANT, FOLLOWING INSTILLATION OF SILVER NITRATE SOLUTION}

BY

\author{
J. G. F. Heal, M.I., C.M., London.
}

THE child was born at 10.30 a.m. on April 20, 192\%. As the mother was believed to have gonorrhoea, the medical attendant ordered 1.5 per cent. solution of silver nitrate to be dropped into the infant's eyes three times a day.

The child was first seen by me thirty-four hours after birth. It was ascertained that the silver nitrate had been instilled into each eye on at least five occasions. The lids of both eyes were slightly swollen, and the margins hyperaemic, The right eye: 